wo dieser im Kontext der in den "neuen Kirchengesetzen" enthaltenen sogenannten Arierparagrafen auch auf die >Widerstandsbewegung ‘ gegen antijüdische Tendenzen bzw. Maßnahmen im Bereich der Literatur einging. Bei Jaesrich war dazu zu lesen:

[E]ine sichtbare geistige Resistance [konnte sich] auch nur dort ansiedeln, wo Staat und Partei im Interesse irgendwelcher ihnen genehmer Werte ein Auge zudrückten. So wurde das Buch vom Soldatenkönig für die Wehrmacht in größeren Partien gekauft, ungeachtet der Tatsache, daß sein »jüdisch versippter « Autor nur dank einer zeitlich begrenzten Sondergenehmigung der Reichsschrifttumskammer überhaupt publizieren durfte, unbeschadet der Tatsache auch, daß es für jeden, der Ohren hatte zu hören, in ganz anderen Tönen als den erwünschten sprach. So gefiel »Der Vater« Rudolf Alexander Schröder und Rudolf Pechel, gefiel aber auch Hans Hinkel und Reichsinnenminister Frick. Doch weder das noch die unzähligen Interventionen, die Telefonate, Besuche, Briefe, über die Klepper genaueste Buchführung ablegt, konnten das Zuschnüren der Arisierungsschlinge aufhalten, die sich seit dem 9. November 1938 und erst recht seit Kriegsbeginn immer schneller zuzog. ${ }^{92}$

\title{
1.6 Der Zweite Weltkrieg und der deutsche Widerstand
}

Der mit Abstand größte Teil der Veröffentlichung zur Geschichte des >Drittes Reiches im Monat bezog sich auf den für Deutschland nur wenige Jahre zuvor mit einer totalen militärischen und politischen Niederlage zu Ende gegangenen Zweiten Weltkrieg. Einen zweiten Schwerpunkt bildete in diesem Kontext der konservative militärische Widerstand gegen den immer wieder als "Hitlerstaat« apostrophierten Nationalsozialismus, der in erster Linie vonseiten einer Minderheit aus der deutschen Militärelite erfolgte. Auch weil in einigen Beiträgen der enge Zusammenhang zwischen dem Zweiten Weltkrieg und dem »deutschen Widerstand « fokussiert und angesprochen wurde, werden in diesem Abschnitt beide Themenbereiche gemeinsam behandelt. Abgesehen von den Beiträgen, die quasi in totalitarismustheoretischer Perspektive geschrieben wurden, untersuchte und thematisierte Der Monat den Zweiten Weltkrieg (sowie dessen unmittelbare Vorgeschichte) explizit und implizit in 22 Beiträgen, den »deutschen Widerstand « in elf Beiträgen..$^{93}$ Die Auswertung der einzelnen Ausgaben des Monat ergab, dass auf den facettenreichen, komplexen sozialdemokratischen und kommunistischen (Partei-)Widerstand ${ }^{94}$ (wie z.B. von Löwenthal oder Borkenau) sowie auf den individuellen bzw. organisierten jüdischen Widerstand (wie z. B. von

92 Jaesrich, In Qualen gelebt, S. 73

93 Hierbei wurden auch Beiträge berücksichtigt, die nicht ausdrücklich den militärischen und politischen Kontext des Zweiten Weltkrieges untersuchten und thematisierten, sondern bereits auch auf den deutschen bzw. christlichen Widerstand im Verlauf der 1930er-Jahre eingingen. Siehe hierzu bes. Jaesrich, In Qualen gelebt, S. 73.

94 Der Begriff »Widerstand« wird hier verstanden als nicht ausschließlich militanter, d. h. militärischpolitischer Kampf gegen den Nationalsozialismus, sondern auch als eine Auseinandersetzung, die gewissermaßen eine politisch-intellektuelle und politisch-humanistische Form annehmen konnte, indem man in Zeitungs-, Zeitschriften- oder auch Buchveröffentlichungen gegen »Hitlerdeutschland « kämpfte; oder indem man auf wissenschaftlichen Symposien - wie zum Beispiel Hans Kohn Forschungsarbeiten zur Analyse des Nationalsozialismus präsentierte, oder indem man - wie zum Beispiel Hannah Arendt - in jüdischen (Flüchtlings-)Bewegungen arbeitete. 
Arendt, Aron oder Kohn) ${ }^{95}$ gegen die nationalsozialistische Herrschaft konkret nicht eingegangen wurde; wenn man einmal davon absieht, dass das Zeitschriftenorgan im Kontext der (vergleichenden) Auseinandersetzung mit dem Totalitarismusphänomen und der Renegatenliteratur auch diesen Komplex in den Brennpunkt des Interesses rückte. ${ }^{96}$

Mit den folgenden Ausführungen ist in erster Linie beabsichtigt:

1. Den auf breiter Dokumenten- und Quellenbasis geschriebenen und nicht zuletzt die diplomatische Vorgeschichte des Zweiten Weltkrieges - mit dem Fokus der nationalsozialistischen respektive hitlerschen Außenpolitik vom »Anschluss« Österreichs bis zum Überfall der Wehrmacht auf Polen - untersuchenden Beitrag Diplomatie aufschiefer Bahn von Joachim G. Leithäuser ausführlich darzustellen, da diese vierteilige Reihe die umfassendste und genaueste Untersuchung in diesem Kontext verkörperte.

2. Die Benennung der zentralen und mithin wichtigsten Beiträge des Monat zum Themenkomplex »Der Zweite Weltkrieg und der deutsche Widerstand«, die zudem in aller Kürze in ihren wesentlichen Inhalten, den entsprechenden Kernaussagen sowie -interpretationen wiedergegeben werden.

3. Die Benennung der Autoren und der einzelnen Beiträge, die sich mit dem angesprochenen Themenkomplex auseinandergesetzt haben.

Hierbei ist es selbstverständlich nicht möglich und kann keinesfalls das Ziel dieses Abschnitts sein, die aufgeführten Veröffentlichungen im Monat zu diesem Themenkomplex in extenso wiederzugeben bzw. zu referieren. Insofern wird in diesem Abschnitt häufig ein historisches Wissen vorausgesetzt.

Der zentrale Beitrag im Monat, der sich mit dem Beginn des Zweiten Weltkrieges, d. h. dem Überfall der deutschen Wehrmacht auf Polen am 1. September 1939, und den historischen Ereignissen im Zusammenhang mit den außenpolitischen Zielen des Nationalsozialismus, besser: Hitlers außenpolitischen Maßnahmen und diplomatischen Methoden in den Jahren vor dem Krieg auseinandersetzte, war die in vier Teilen, auf breiter Dokumentenbasis erschienene wissenschaftliche, fast 250 Seiten umfassende Studie Diplomatie auf schiefer Bahn von Joachim G. Leithäuser. ${ }^{97}$ Das Buch des prominenten Autors des Monat wurde in leicht gekürzter Fassung vorab, einschließlich des fast kompletten Fußnotenapparates veröffentlicht. ${ }^{98}$ Die einzelnen Kapitel lauteten:»I.

95 Siehe die entsprechenden Hinweise in den jeweiligen Porträts in Kap. II.4.

96 Siehe hierzu bes. die (Teil-)Veröffentlichung des autobiografischen Renegatenberichtes Georg $\mathrm{K}$. Claser, Geheimnis und Cewalt. Ein Bericht, Stuttgart/Hamburg 1953, in: Der Monat 4 (1951), H. 37 , S. 3-37; H. 38, S. 155-182; H. 39, S. 270-302; H. 40 (1952), S. 372-402.

97 Joachim G. Leithäuser, Diplomatie auf schiefer Bahn, Frankfurt a. M. 1953. Der zum damaligen Zeitpunkt in Berlin als freier Schriftsteller lebende Leithäuser zählte zu den Autoren des Monat, die dort frühzeitig und häufig zu unterschiedlichen Themen veröffentlichten.

98 Leithäuser stützte sich in seiner Studie u. a. auf folgende historische Quellen bzw. Dokumente: Akten zur Deutschen Auswärtigen Politik (1918-1945). Serie D (1937-1945); Dokumente zur Vorgeschichte des Krieges (Weißbücher des Auswärtigen Amtes); Der Prozeß gegen die Hauptkriegsverbrecher vor dem Internationalen Militärgerichtshof; Das Urteil im Wilhelmstraßen-Prozeß, SchwäbischGmünd 1950. Zudem stützte er sich auf folgende shistorische Darstellungen«: Walther Hofer, Die Europäischen Mächte und der Ausbruch des Zweiten Weltkrieges, Stuttgart o. J.; Heinz Holldack, Was 
Der Fall Österreich «, ${ }^{99} » 2$. Der Fall Tschechoslowakei ${ }^{100}$ und der anschließende zweite Teil zum »Fall Tschechoslowakei ${ }^{101}$ sowie der vierte und abschließende Teil »3. Der Fall Polen «. ${ }^{102}$ Worum es Leithäuser nicht zu tun war, war unter anderem die Untersuchung sowie Analyse der weltanschaulichen Komponente und der grundsätzlichen außenpolitischen Ziele Hitlers in diesem Kontext ausdrücklich in den Fokus zu rücken.

In der redaktionellen Einführung zum ersten Teil von Diplomatie auf schiefer Bahn hieß es hinsichtlich der Begründung und der Motivation für die Veröffentlichung:

Während zur Zeit der Hitlerherrschaft streng geheim gehalten wurde, was sich in den politischen Befehlszentralen abspielte, steht seit ihrem Zusammenbruch fast mehr urkundliches Material zur Verfügung als über irgendeine andere historische Epoche. Kaum eine Generation konnte soviel über die Geschichte ihrer Zeit erfahren wie die unsere. Und doch machen nur wenige von dieser Möglichkeit Gebrauch: man neigt dazu, die Ereignisse der jüngsten Vergangenheit zu vergessen, obwohl sie nicht nur als Teil der deutschen Ceschichte, sondern als Musterbeispiele für die geistige Haltung und Praxis antidemokratischer Systeme aufschlußreich sind. Was seit 1945 über die Ära des Nationalsozialismus geschrieben worden war, konnte zwar auf unübersehbare Mengen amtlicher Dokumente Bezug nehmen, doch begegnete es auch vielen Zweifeln und Ressentiments; es war »mit dem Odium höchst unpopulärer Gerichtsverfahren « behaftet und in den unseligen Streit um die Kollektivschuld hineingerückt. Die Memoiren der beteiligten Persönlichkeiten brachten weitere Aufschlüsse über weitere Vorgänge, ohne daß sich immer unterscheiden ließ, wie weit neben der Absicht der historischen Berichterstattung die der eigenen Rechtfertigung mitsprach. Außerdem setzte bald eine Springflut mehr oder weniger wichtiger Figuren des Hitlerreichs ein, die an das Sensationsbedürfnis oder ein verschwommenes Mitgefühl der Leser appellierten. Bis die berufenen Historiker nach der Herbeischaffung und Gegenüberstellung selbst der nebensächlichsten Unterlagen die endgültigen Darstellungen dieser Epoche hervorbringen, wird sicher noch einige Zeit vergehen. Kurze und nüchterne Zusammenfassungen aus der Fülle des Materials jedoch können schon heute die Antwort auf viele Fragen geben: waren die Politiker der Hitlerzeit genial oder dumm, waren sie Dämonen oder Dilettanten, konnten sie »Ceschichte machen« oder war ihr Mißerfolg unvermeidlich? Wie kam es zu den »Erfolgen« des Jahres 1938, warum brach der Krieg aus? Man sollte diese Fragen aus eigenem politischen Urteilsvermögen beantworten, doch

wirklich geschah. Die diplomatischen Hintergründe der deutschen Kriegspolitik, München 1949; de Mendelssohn, Die Nürnberger Dokumente; L. B. Namier, Diplomatisches Vorspiel (1938-1939), Berlin 1949 sowie auf folgende »Erinnerungen«: Birger Dahlerus, Der letzte Versuch, München 1948; André François-Poncet, Als Botschafter in Berlin, Mainz 1951; Ulrich v[on] Hassell, Vom anderen Deutschland. Aus den nachgelassenen Tagebüchern 1938-1944, Zürich 1946; Erich Kordt, Wahn und Wirklichkeit, Stuttgart 1948; Franz v[on] Papen, Memoirs, London 1952; Kurt v[on] Schuschnigg, Ein Requiem in Rot-Weiß-Rot, Zürich 1946; Ernst v[on] Weizzäcker, Erinnerungen, München 1950.

99 Joachim G. Leithäuser, Diplomatie auf schiefer Bahn. I. Der Fall Österreich, in: Der Monat 4 (1952), H. 48, S. 614-634.

100 Ders., Diplomatie auf schiefer Bahn. 2. Der Fall Tschechoslowakei, in: Der Monat 5 (1952), H. 49, S. 49-68.

101 Ders., Diplomatie auf schiefer Bahn. 2. Der Fall Tschechoslowakei (Schluß), in: Der Monat 5 (1952), H. 50, S. 195-206.

102 Ders., Diplomatie auf schiefer Bahn. 3. Der Fall Polen, in: Der Monat 5 (1952), H. 51, S. 282-310. 
man braucht dazu eine genaue Kenntnis der Einzeltatsachen, die seit Veröffentlichung der »Akten zur Deutschen Auswärtigen Politik 1937-1945« zugänglich sind. Unsere Darstellung, [...], macht den Versuch, in ihren wichtigsten Umrissen die vier großen mitteleuropäischen Krisen zu schildern, die dem Krieg voraufgingen und ihn schließlich hervorriefen: den Anschluß Österreichs, die Konferenz von München, den Vorstoß nach Prag und die Bedrohung Polens. Sie läßt nur die Tatsachen sprechen, die schnell ihre eigene Dramatik entfalten, und ist bis ins einzelne dokumentarisch belegt. ${ }^{103}$

Leithäuser zeigte im ersten Teil Der Fall Österreich, dass im Rahmen von Hitlers außenpolitischen Ambitionen der »Anschluss« Österreichs an Deutschland von Anbeginn ein zentrales Ziel war. Hierbei wurde zur Erreichung dieses Zieles gewissermaßen eine »totalitäre Politik« ins Zentrum gerückt, in deren Kontext der Zweck die Mittel heiligte. »Von Deutschland her versuchte man es zunächst mit der Politik des direkten und indirekten Druckes: Propagandakrieg, Terrorakte, Wirtschaftsboykott waren die bevorzugten Mittel. [...] Den Schlußakt dieser brachte der Putsch vom 25. Juli 1934, in dessen Verlauf der Bundeskanzler Dollfuss ermordet wurde« (S. 615). Dessen Nachfolger Kurt von Schuschnigg machte Hitler in einer Unterredung im Jahre 1938 dezidiert klar, dass er als »Führer des Deutschen Reiches« einen geschichtlichen Auftrag hatte, den er zu erfüllen gedenke, »weil mich«, so Hitler, »die Vorsehung dazu bestimmt hat. Ich bin felsenfest durchdrungen und glaube daran." Die sogenannte österreichische Frage gedachte Hitler in jedem Falle entsprechend seiner Vorstellung zu lösen, »und zwar so oder so!« Für Leithäuser stand fest, dass dies ein vielsagender Ausspruch war, »denn nach Hitlers Terminologie konnte damit nur >so gemeint sein, nämlich mit Gewalt« (S. 620). Hitler unterrichtete Schuschnigg, dass er sich als »den Erlöser « betrachtete, der auch die österreichische Bevölkerung endlich retten wolle und drohte ihm - vor dem Hintergrund der wenige Tage nach dem Gespräch geplanten Rede Hitlers an die »deutsche Nation« vor dem Reichstag - für den Fall, dass er nicht seinen Erwartungen gemäß agiere. »Wenn ich ihnen das sage«, so Hitler zum österreichischen Kanzler Schuschnigg, wie dieser nach Kriegsende in seinem 1946 erschienenen Buch Ein Requiem in Rot-Weiß-Rot berichtete, »dann tun Sie gut daran, mich wörtlich zu nehmen. Ich bluffe nicht. Meine ganze Vergangenheit beweist dies nur zur Genüge. Ich habe noch alles erreicht, was ich wollte, und bin vielleicht dadurch zum größten Deutschen der Geschichte geworden« (S. 621).

Um seine Drohung zu untermauern, fanden in der Folge Truppenaufmärsche und Manöver an der deutsch-österreichischen Grenze statt, die nach Ansicht von Leithäuser insbesondere als »Einschüchterungsversuch« (S. 624) gedacht waren. Nachdem sich nicht zuletzt durch den neuen Außenminister Lord Halifax im Februar 1938 die britische »Appeasementpolitik« unter Chamberlain Bahn gebrochen hatte und nach dem »Berchtesgadener Abkommen« die österreichischen Nationalsozialisten durch politische Aktionen und Demonstrationen die Regierung um Schuschnigg unter Druck setzten, beschrieb Leithäuser ausführlich, wie die politische Krise in Österreich von Berlin aus radikalisiert wurde - insbesondere durch den nationalsozialistischen Minister Arthur Seyß-Inquart, der im Februar 1938 zum Mitglied der Regierung Schuschniggs avancierte. Unter Androhung physischer Gewalt wurde Schuschnigg

103 Redaktionelle Einführung zu Joachim G. Leithäuser, Diplomatie auf schiefer Bahn. 1. Der Fall Österreich, in: Der Monat 4 (1952), H. 48, S. 614. 
gezwungen, im März 1938 von seinem Amt zurückzutreten (S. 631), sodass die Nationalsozialisten »die Straßen« beherrschten (ebd.) und Seyß-Inquart zu dessen Nachfolger aufstieg. Unter dem Druck Berlins forderte er deutsche Truppen an und nach der Entscheidung Hitlers marschierten diese im März 1938 in Österreich ein.

»Die deutschen Truppen und Hitler«, so Leithäuser,

wurden in Österreich mit stürmischem Jubel begrüßt, der sich in Linz fast bis zur Raserei steigerte. [...] Da man die Opposition sofort ausgeschaltet hatte - während des »Anschlusses «wurden etwa 10 ooo Personen verhaftet-, gab es keinerlei Gegenwehr. Es zeigte sich, daß die beste Propaganda der Erfolg ist; [...] Menschen, die kurz zuvor noch für Schuschnigg gestimmt hätten, bereiteten jetzt ihrem zukünftigen Diktator einen triumphalen Empfang. Furcht und Gewalt, Hoffnung und Illusion wirkten zusammen, um ein massenpsychologisches Phänomen zu erzeugen, das jedem Betrachter der modernen Geschichte zu denken geben muß. ${ }^{104}$

Die zeitgenössische Schicksalsfrage für Deutschland zum einen und für die gesamte Welt zum anderen lautete für Leithäuser nach dem »Anschluss« Österreichs: „War dies das Ende oder der Anfang? Das Ende eines Prozesses, der durch Eingliederung des Saarlandes und Österreichs das `Großdeutsche Reich`schuf, größer als das Bismarckreich, oder der Anfang einer abenteuerlichen Eroberungsstrategie?« Zur Beantwortung dieser Frage zitierte er zum Abschluss des ersten Teils von Diplomatie aufschiefer Bahn eine Tagebucheintragung von General Jodl. Dieser schrieb hierzu:

Nach der Annexion Österreichs erwähnt der Führer, daß es mit der Lösung der tschechischen Frage keine Eile habe, weil Österreich zuerst verdaut werden müsse. Nichtsdestoweniger müssen Vorbereitungen für den Fall »Crün« energisch ausgeführt werden; sie werden neuerlich auf der Grundlage der veränderten strategischen Lage wegen der Annexion Österreichs vorbereitet werden müsse. ${ }^{105}$

Leithäusers Veröffentlichung Diplomatie auf schiefer Bahn thematisierte - wie gesagt - die diplomatische Vorgeschichte des Zweiten Weltkrieges. Der zweite Teil in Heft 49 stellte den Versuch dar, die sogenannte Sudetenkrise bis zum Münchener Abkommen $1938 \mathrm{zu}$ schildern. Aus Raumgründen ist es hier unmöglich - wie bereits im »Fall Österreich « - ausführlicher auf die auf breiter Quellenbasis erstellte minutiöse Beschreibung des »Falles Tschechoslowakei« einzugehen. Nur soviel - zumal Leithäuser in diesem Zusammenhang auch gewissermaßen auf den Ursprung des »deutschen Widerstandes« zu sprechen kam. Angesichts des erklärten deutschen Zieles, den Anschluss des Sudetenlandes an das Deutsche Reich zu erreichen und der Forderung »Heim ins Reich«, legte Hitler, so Leithäuser, gemeinsam mit den Generälen Brauchitsch und Keitel am 4. September 1938 fest, dass die Wehrmacht am 28. September »aufmarschieren sollte«. Nach dem »83 Sudetendeutsche wegen Waffen-

104 Ebd., S. 633. Weiter schrieb der Autor an dieser Stelle auf S. 633: »Vor einer riesigen Menschenmenge auf dem Heldenplatz in Wien rief Hitler jene Worte aus, die einem ehemaligen Meldegänger als die für diese Gelegenheit feierlichsten und erhabensten einfallen mußten: >Als Führer und Reichskanzler der deutschen Nation und des Reiches melde ich vor der Geschichte nunmehr den Eintritt meiner Heimat in das Deutsche Reich!«

105 Ebd., S. 634. 
schmuggel und Spionage« verhaftet wurden und »angeblich« ein Abgeordneter der "Sudetendeutschen Partei« von einem Polizeibeamten geschlagen wurde, nutzte die nationalsozialistische Führungsspitze diese Situation aus. Auf dem in Nürnberg stattgefundenen >Reichsparteitag Großdeutschland »donnerte« Göring und »krönte« Hitler »seine Parteitagrede mit lauten Drohungen:

Ich kann aber den Vertretern dieser [westlichen] Demokratien nur sagen [...], daß, wenn diese gequälten Kreaturen [gemeint waren die Sudetendeutschen] kein Recht und keine Hilfe für sich selbst finden können, sie beides von uns bekommen werden [...]. Ich werde aber unter keinen Umständen gewillt sein, einer weiteren Unterdrückung der deutschen Volksgenossen in der Tschechoslowakei in endloser Ruhe zuzusehen [...]. Die Deutschen in der Tschechoslowakei sind weder wehrlos noch sind sie verlassen. Das möge man zur Kenntnis nehmen. ${ }^{106}$

Am 15. September 1938 empfing Hitler den englischen Premierminister Neville Chamberlain auf dem Obersalzberg bei Berchtesgaden, der - wie Leithäuser berichtete sich zunächst die überaus langen Ausführungen Hitlers geduldig anhören musste und mit dessen Hassausbrüchen konfrontiert wurde, als Hitler über »die Tschechen« sprach (S. 57). Letzten Endes zeigte sich Chamberlain mit Hitlers Forderung einverstanden, das Selbstbestimmungsrecht der Völker anzuerkennen. Mithin versprach er, einerseits der Annexion der Sudetengebiete keine Hindernisse in den Weg zu legen sowie andererseits mit der französischen Regierung gemeinsam Druck auf den tschechischen Präsidenten Benesch auszuüben. Nach der Abreise des sich um den Erhalt des Friedens sorgenden Chamberlains schilderte Hitler, so Leithäuser, »Ribbentrop und Weizsäcker die Unterhaltung. >Er klatschte sich in die Hände wie nach einem höchst gelungenen Vergnügen. Er hatte das Gefühl, den trockenen Zivilisten in die Ecke manövriert zu haben<, berichtet Weizsäcker. ${ }^{107}$ Nach dem zweiten Treffen zwischen Hitler und dem englischen Premierminister, das vom 22. bis zum 23. September 1938 in Bad Godesberg stattfand, reiste Chamberlain, aufgrund von gewissen Zugeständnissen, die Hitler zu machen bereit war, zufrieden ab und glaubte, dass zwischen ihm und dem deutschen Staatsoberhaupt "ein Vertrauensverhältnis entstanden" sei (S. 62). Hitler wiederum befahl wenige Tage darauf, dass am 30. September der Angriff auf die Tschechoslowakei beginnen soll.

Der drohende Krieg war nach dem Dafürhalten von Leithäuser der konkrete Hintergrund dafür, dass sich zwar keine »Opposition gegen das allgegenwärtige System« bilden konnte. Indes gab es

in den Spitzen des Heeres und der Beamtenschaft einige Männer mit Einfluß, die [...] das Land vor den verhängnisvollen Folgen leichtsinniger Abenteurerpolitik zu schützen suchten: an der Spitze Beck, der frühere, und Halder, der amtierende Chef des Ceneralstabes, weiterhin zählten Canaris, Kordt und Weizsäcker zu ihnen, auch der Oberbefehlshaber, v[on] Brauchitsch, [...]. Die Sudetenkrise brachte die größte Gefährdung, der das Hitlersystem jemals von innen ausgesetzt war. Die Vorbereitungen zum Staats-

106 Joachim G. Leithäuser, Diplomatie auf schiefer Bahn. 2. Der Fall Tschechoslowakei, in: Der Monat 5 (1952), H. 49, S. 56.

107 Ebd., S. 58. 
streich waren so weit gediehen, daß sowohl zwischen dem 14. und 18. September wie am 28. September Hitlers Verhaftung bevorstand. Das erste Mal warf Chamberlains Intervention, das zweite Mal die Ankündigung der Münchener Konferenz diese Pläne um, da das Unternehmen nur dann gelingen konnte, wenn Hitler den Angriffsbefehl erteilt hatte und damit vor aller Welt und besonders vor dem deutschen Volke deutlich als Kriegsanstifter gekennzeichnet war; denn infolge der staatsgelenkten Information und Propaganda ahnte die deutsche Bevölkerung nichts von Hitlers Angriffsplänen und hielt ihn bösartiger Absichten nicht für fähig. Die Münchener Konferenz beraubte die Verschworenen der Möglichkeit, das wahre Wesen der Hitlerpolitik zu enthüllen, und die Gelegenheit, Deutschland vor dem Verderben zu retten, war dahin. ${ }^{108}$

Nach Abschluss des Münchener Abkommens im Rahmen der Konferenz vom 29./30. September $1938^{109}$ und der unter dem Druck deutscher Kriegsdrohung von England und Frankreich quasi erzwungenen Anerkennung der Vereinbarungen durch die tschechische Staatsführung - d.h. vor allem die Abtretung des Sudetenlandes an Deutschland, das daraufhin von der Wehrmacht besetzt wurde - kam alsbald der "nächste Schlag«. Der Überfall auf Prag im Frühjahr durch die deutschen Truppen im Frühjahr $1939^{110}$ löste nach Meinung der Redaktion des Monat »eine entscheidende Wendung in der diplomatischen Vorgeschichte des zweiten Weltkrieges aus«. Denn nach der Annexion Österreichs, der Sudetenkrise sowie dem Münchener Abkommen sollte dies - bevor die Wehrmacht dann am 1. September 1939 Polen überfiel - die letzte unblutige Eroberung des nationalsozialistischen Regimes sein. ${ }^{111}$

Mit dem »Fall Polen« setzte sich Leithäuser im letzten Teil seiner Veröffentlichung Diplomatie aufschiefer Bahn auseinander. Hierzu schrieb die Redaktion des Monat in der Einleitung, dass es dem Autor weniger um die »Erhellung einzelner diplomatischer Vorgänge« ging als »vielmehr um die Sichtbarmachung des Wesentlichen, des Geistes bzw. des Ungeistes, aus dem heraus ein ganzer Erdteil der Katastrophe preisgegeben wurde $\ll^{112}$.

108 Ebd., S. 66.

109 Siehe hierzu die Details in ebd., S. $66 \mathrm{ff}$.

110 Zur Umsetzung des Münchener Abkommens und zur politischen sowie insbesondere diplomatischen Vorgeschichte bis zur Besetzung Prags im März 1939 sowie zum »Bankrott der AppeasementPolitik« siehe Joachim G. Leithäuser, Diplomatie auf schiefer Bahn. 2. Der Fall Tschechoslowakei (Schluß), in: Der Monat 5 (1952), H. 50, S. 195-206. Unter der Überschrift Die Juden sind Schuld schrieb Leithäuser im Zusammenhang mit der »udenfrage « in der Tschechoslowakei u. a., dass wenige Monate zuvor »jenes beschämende, von gewissenlosen Elementen organisierte Ereignis der Kristallnacht «stattgefunden (hatte); jetzt verkündete Hitler: `Die Juden werden bei uns vernichtet. Den 9. November 1918 haben die Juden nicht umsonst gemacht, dieser Tag wird gerächt werden. Aber in der Tschechoslowakei vergiften die Juden heute noch das Volk.« Und weiter hieß es an selber Stelle in bezug auf das Schicksal von 2000 tschechischen Juden, die in einem »Lager konzentriert « wurden: »Hitler verwies auf die >Möglichkeit<, daß die Staaten, >die daran interessiert sind, irgendeinen Fleck in der Welt nehmen und dort die Juden hinsetzen und den angelsächsischen, humanitätstriefenden Staaten dann sagen: Hier sind sie; entweder verhungern sie, oder ihr setzt eure vielen Reden in die Praxis um.«(Ebd., S. 199)

111 So die redaktionelle Einführung in ebd., S. 195.

112 Redaktionelle Einführung in: Joachim G. Leithäuser, Diplomatie auf schiefer Bahn. 3. Der Fall Polen, in: Der Monat 5 (1952), H. 51, S. 282-310, hier S. 282. 
Vor dem Hintergrund der Beschreibung der "freundschaftlichen« Beziehung zwischen Deutschland und Polen der zurückliegenden Jahren stellte Leithäuser fest, dass mit der Besetzung des Sudetenlandes durch deutsche Truppen gegenüber Polen »ein anderer Ton angeschlagen wurde« (S. 283). Er schilderte, wie beispielsweise der deutsche Außenminister Ribbentrop dem polnischen Botschafter Lipski einige »Vorschläge« (im Sinne) Hitlers im Kontext der sogenannten Generalbereinigung des deutschpolnischen Verhältnisses übermittelte: unter anderem »Rückgliederung Danzigs ins Reich", "Auswanderung der Juden aus Polen« sowie eine "gemeinsame Politik gegenüber Rußland auf der Basis des Antikominternpakts« (S. 284). Polen zeigte sich, so Leithäuser, zur Zusammenarbeit bereit, lehnte allerdings die »unzweideutige Forderung« Hitlers nach »Rückkehr Danzigs ins Reich ab«(S. 284).

Nach der »Garantieerklärung« Englands zur Verhinderung weiterer außenpolitischer Expansion ${ }^{113}$ unternahm Roosevelt einen diplomatischen Versuch - eingedenk der Tatsache, dass in der Vergangenheit Hitler jedwede Form von Verträgen nach persönlichem Gusto brach - und machte mit dem sogenannten Appell vom 15. April 1939 Hitler das Angebot, den Weltmarkt für die Deutschen zu öffnen - unter der Voraussetzung, dass dieser den Frieden garantiere. Hitler indes beauftragte, so Leithäuser, die »deutsche Presse« in scharfer Form auf »der ersten Seite«, seine eindeutige Ablehnung zu kommentieren; er selbst antwortete am 26. April »vor dem deutschen Reichstag«, indem er Roosevelt »lächerlich « machte (S. 286).

Aufgrund der Ablehnung Polens gegenüber den »freundlichen Forderungen des Hitlerreichs« entschloss sich Hitler nach Ansicht von Leithäuser, »daß Polen nur mit Gewalt zum Nachgeben gezwungen werden konnte. Schon am 3. April 1939 wurde die 'Weisung für die Wehrmacht 1939/40< herausgegeben und mit ihr die Invasion Polens (Deckname: >Fall Weiß«) energisch vorbereitet.« Und in einer zweiten »Weisung« vom 11. April hieß es zum »Fall Weiß«, dass ebendieser »als >vorsorgliche Ergänzung der Vorbereitungen<, deren Hauptziel die >Auseinandersetzung mit den Westgegenern war.« Hitler »wollte unbedingt einen Zweifrontenkrieg vermeiden und hielt es für möglich, erst die Westmächte zu besiegen und danach Polen zu erledigen « ${ }^{114}$.

Nach der propagandistischen Ausschlachtung der Politik gegenüber den sogenannten Volksdeutschen in Polen, ${ }^{115}$ der "Danzig-Krise «, ${ }^{116}$ der politisch-diplomatischen Annäherung Deutschlands an die Sowjetunion, ${ }^{117}$ dem »Hitler-Stalin-Pakt « vom 23. August 1939, ${ }^{118}$ erteilte Hitler General Keitel am 25. August den Befehl, dass die

113 Siehe im Einzelnen ebd., S. $284 \mathrm{ff}$.

114 Ebd., S. 287.

115 Siehe ebd., S. $287 f$.

116 Siehe ebd., S. $291 \mathrm{f}$.

117 Siehe hierzu und zu den »diplomatischen Aktivitäten« Englands und Frankreichs in diesen Tagen, bevor dann am 21. August 1939 in London die Nachricht der bevorstehenden Vertragsunterzeichnung wie eine »Bombe« einschlug, ebd., S. 290-294. Über die Annäherung Hitlers schrieb Leithäuser aufS. 290 u. a.: »Zur Förderung freundlicherer Gefühle in Moskau schlug Hitler einen phantastischen ideologischen Purzelbaum und machte, [...], schmeichelhafte Bemerkungen über den bisherigen ,Weltfeind،, für den ihm zwei Jahrzehnte lang kein Schimpfwort zu stark gewesen war. >lch habe nicht gewußt, welch eine sympathische und kraftvolle Persönlichkeit Stalin ist‘, sagte er beispielsweise, als er Stalin zum erstenmal im Film gesehen hatte.«

118 Siehe ebd., S. $296 \mathrm{ff}$. 
Wehrmacht am nächsten Morgen um 4 Uhr gegen Polen losschlagen soll. ${ }^{119}$ Der Angriff auf Polen wurde von Hitler noch einmal kurzfristig verschoben, da, so Leithäuser, ihm durch das Auswärtige Amt mitgeteilt wurde, dass der Abschluss des Bündnisvertrages zwischen England und Polen stattfand (S. 299). Hitler brauchte "Zeit zu Verhandlungen« insbesondere mit London und wollte vor allem zum einen Chamberlain sowie dem englischen Außenminister Lord Halifax keinen Grund zur Verärgerung liefern und zum anderen seine grundsätzliche »Friedensmission « unter Beweis stellen. ${ }^{120}$

Während die britische Regierung Warschau bat, alles zu unterlassen, was Polen die Verantwortung für einen militärischen Konflikt mit Deutschland »zuschieben könnte « und seine Bereitschaft bekundete, seinen »Bündnispflichten« im Kriegsfall nachzukommen, erging nach Leithäuser gewissermaßen zur selben Zeit, am 30. August, um 12 Uhr 40, »Hitlers >Weisung Nr. 1 für die Kriegsführung«:

Nachdem alle politischen Möglichkeiten erschöpft sind, um auf friedlichem Wege eine für Deutschland unerträgliche Lage an seiner Ostgrenze zu beseitigen, habe ich mich zur gewaltsamen Lösung entschlossen. Der Angriff gegen Polen ist nach den für den »Fall Weiß« getroffenen Vorbereitungen zu führen mit Abänderungen, die sich beim Heer durch den inzwischen fast vollendeten Aufmarsch ergeben.

Angriffstag 1. September 1939. Angriffszeit 4.45 Uhr. ${ }^{121}$

Die noch stattgefundenen Verhandlungen zwischen Göring bzw. Ribbentropp und Vertretern der englischen und polnischen Regierung verliefen ergebnislos; zumal »deutsche Vorschläge« nach Meinung von Leithäuser für Hitler nur als »Alibi« fungierten. Denn: Am 1. September 1939 um 4 Uhr 45 überfiel die Wehrmacht Polen und mithin begann der Zweite Weltkrieg. Am selben Tag um 10 Uhr morgens hielt Hitler eine Rede vor dem Deutschen Reichstag. Hierzu führte Leithäuser aus:

Mit seiner Rede versucht Hitler so gut wie möglich Stimmung zu machen: er gibt noch einmal seine "großzügigen Vorschläge« bekannt, er behauptet, »[l]ch bin dann mit meiner Regierung zwei volle Tage dagesessen und habe gewartet, ob es der polnischen Regierung paßt, nun endlich einen Bevollmächtigten zu schicken oder nicht«, er zetert über polnische Schandtaten wie z. B. einen Überfall auf den Sender Cleiwitz - den er selbst mit SS und Häftlingen aus einem Konzentrationslager in polnischen Uniformen arrangiert hat - und brüstet sich, er habe wieder den Soldatenrock angezogen, der ihm »der heiligste und teuerste war«. Seine Unheilsbotschaft, die er dem deutschen Volk auszurichten hat, kleidet er in die Worte: »Die deutsche Wehrmacht schlägt zurück. « ${ }^{122}$

Ebenfalls mit dem Zweiten Weltkrieg setzte sich der englische Historiker Rohan Butler auseinander - anlässlich der Rezension des Buches Der Zweite Weltkrieg 1939-1945 (Bd. I) von dem Historiker Walter Görlitz. ${ }^{123}$ Butler lobte die umfangreiche, sich aus

119 Ebd., S. 299.

120 Siehe zu den diplomatischen Verhandlungen vor allem zwischen Berlin und London in den späten Augusttagen 1939 die minutiösen Einzelheiten in ebd., S. 300-307.

121 Ebd., S. 308.

122 Ebd., S. 309.

123 Rohan Butler, Das dreidimensionale Stadium, in: Der Monat 4 (1952), H. 44, S. 200-204 (Rezension). 
sehr verschiedenartigem Quellenmaterial erstellte, um Objektivität bemühte Studie Görlitz', obwohl das Buch keine einzige Fußnote enthielt, was die wissenschaftliche Brauchbarkeit erheblich beeinträchtigte. Gleichwohl war er der Auffassung, dass es eine Leistung der genuin militärgeschichtlichen Untersuchung war, insbesondere den qualitativen Unterschied zwischen dem Ersten und Zweiten Weltkrieg herausgearbeitet $\mathrm{zu}$ haben, denn Görlitz hatte festgestellt, »daß >die Kriegführung im 20. Jahrhundert in ein neues, dreidimensionales Stadium getreten ist « ${ }^{124}$.

Neben dem Seekrieg, dem Luftkrieg und dem militärischem Verlauf im »Nahen Osten« zeigte die Studie, so Butler,

die Geschichte der deutschen Armeen, von ihren ersten, noch in der Rückschau überwältigenden Serienfolgen - Polen, Dänemark, Norwegen, Holland, Belgien, Frankreich- bis zu dem verhängnisvollen Rückschlag am Kanal, weiter zu den neuen Eroberungen auf dem Balkan, dem unheilvollen Überfall auf Rußland, dem Versagen vor Moskau und schließlich bis zum Scheitelpunkt des Krieges, der Niederlage bei Stalingrad, mit der die eigentliche Berichterstattung des ersten Bandes schließt. ${ }^{125}$

Im Zusammenhang mit der überragenden Bedeutung, die die Kriegswirtschaft im Allgemeinen für die »moderne Kriegsführung« besaß, insistierte Butler auf die Bedeutung der »wirtschaftlichen Seite des Krieges« und brachte vor dem Hintergrund der Erkenntnisse der "Görlitz-Studie« seine Überraschung zum Ausdruck, dass besonders im »nationalsozialistischen Führerstaat die weitblickende Planung und Koordination von oben ganz offensichtlich gefehlt haben«. Im Unterschied zu England begegnete Hitler, so Butler, »jeder neuen Schwierigkeit mit seiner Lieblingsmethode, der Ernennung eines neuen >Sonderbevollmächtigten« «, und trug damit schließlich zu einem »schier unentwirrbaren Kompetenzkampf« bei. ${ }^{126}$

Ausdrücklich bemängelte Butler an der Studie zum Zweiten Weltkrieg von Görlitz, dass dieser vor dem Hintergrund seiner »einfühlsame[n] Schilderung von den Schwierigkeiten der deutschen Generalität« eine »Unterlassungssünde« beging. Diese bestand darin, dass Görlitz einerseits die Zwangsarbeit von »Fremdarbeitern« nicht oder nur unzureichend thematisierte, obwohl sie Butler zufolge »oft unter haarsträubenden Bedingungen für die von ihnen meist verabscheute Diktatur zu arbeiten gezwungen waren «, und andererseits mit Blick auf die wirtschaftlichen Aspekte des überwiegend aus politischen und weltanschaulichen Gründen geführten Krieges bei-

124 Ebd., S. 201.

125 Ebd.

126 Ebd., S. 203 (Hervorh. des Verf.). Siehe hierzu auch S. 204, wo Butler auf der Grundlage der Studie von Görlitz ebendiesen Kompetenzkampf anhand des Beispiels des Rüstungsministers Albert Speer erläuterte, der nämlich »einen erbitterten Ressortkampf mit den ihm nicht unterstellten Rüstungsträgern vor allem der Luftwaffe«, auszufechten hatte«. Darüber hinaus erwähnte er an gleicher Stelle die »mangelhafte Koordinierung auf militärischem Gebiet« insbesondere zwischen dem Oberkommando der Wehrmacht sowie dem Oberkommando des Heeres, was seinem Urteil nach in erster Linie an einem »Mangel« von Adolf Hitler und zudem an den »rivalisierenden Parteipaladine[n] Himmler und Göring «lag. Zum Kompetenzkampf im NS-System vgl. auch ders., Der Fall Fritsch. 
spielsweise nicht »auf die organisierten Plünderungen, die Konzentrationslager und die Verbrechen gegen die Menschlichkeit« einging. ${ }^{127}$

So ausführlich der Monat die diplomatische und außenpolitische Genesis des Zweiten Weltkriegs thematisierte und untersuchte, um so geringer fiel die substanzielle Auseinandersetzung mit dem nationalsozialistischen »Unternehmen Barbarossa« aus. Mit anderen Worten: Grundsätzliche Erkenntnisse beispielsweise über politische Ziele und weltanschauliche Motive des NS-Herrschaftsregimes bzw. der Führungsspitze um Hitler, Göring und Himmler erfuhr man als Leser der Zeitschrift insbesondere indirekt aus totalitarismustheoretischer Perspektive. Neben der Veröffentlichung von den beiden Kapiteln Totalitäre Propaganda und vor allem Die Geheimpolizei aus der 1951 erschienenen Totalitarismusstudie von Arendt vermittelte besonders der dreiteilige Beitrag Der Fall Wlassow von George Fischer, ${ }^{128}$ einem wissenschaftlichen Mitarbeiter des Russian Research Center der Harvard-Universität, ${ }^{129}$ konkrete und wichtige Erkenntnisse. Darüber hinaus rückte der deutsche Überfall auf die Sowjetunion im Monat auch im Kontext der »Memoirenliteratur« in das Blickfeld des Erkenntnisinteresses.

In Fischers Veröffentlichung, die ein Ergebnis der Kommunismusforschung war, weil es insbesondere um den Totalitarismus sowjetischer Couleur ging, ${ }^{130}$ waren gleichwohl substanzielle Erkenntnisse über politische, psychologische und weltanschauliche Motive für den nationalsozialistischen Krieg gegen die Sowjetunion sowie über konkrete historische Tatsachen der »deutsche[n] Ostpolitik« zu erfahren. Vor dem Hintergrund des Phänomens der antistalinistischen sowjetischen »Kollaborationsbewegung« mit dem Nationalsozialismus schrieb er beispielsweise im ersten Teil zum Fall Wlassow (um den es im Folgenden selbstverständlich nur insoweit gehen kann, als

127 Butler, Das dreidimensionale Stadium, S. 204.

128 Ceorge Fischer, Der Fall Wlassow, in: Der Monat 3 (1951), H. 33, S. 263-279; ders., Der Fall Wlassow (Fortsetzung), in: Der Monat 3 (1951), H. 34, S. 393-408, sowie ders, Der Fall Wlassow (Schluß), in: Der Monat 3 (1951), H. 35, S. 519-525. In der redaktionellen Einleitung anlässlich der ersten Veröffentlichung war im H. 33, S. 263 u. a. zu lesen: »Was läßt den Fall Wlassow so faszinierend und bezeichnend erscheinen? Einmal der Umstand, daß er ein völlig neues Licht auf die deutsche Niederlage im zweiten Weltkrieg wirft, zum andern, daß er die psychologische, moralische und politische Beschaffenheit des von einem modernen totalitären System versklavten Individuums verdeutlicht. Obgleich das Problem der Kollaboration und der Selbsterhaltung innerhalb einer Diktatur für Millionen Menschen zu einem traumatischen Erlebnis von größter Tragweite geworden ist, haben es bisher weder der kleine Mann noch der Politiker und Intellektuelle - auch der historische Forscher nicht - seiner ganzen Bedeutung nach erkannt. [...] Der Fall des sowjetischen Ceneralleutnants Wlassow und seiner antistalinistischen Bewegung ist wie kein zweiter geeignet, ihr die Frage nach der inneren Struktur und äußeren Stärke des Totalitarismus zu beantworten.«

129 So die redaktionelle Mitteilung der Zeitschrift über den Autor, in: Der Monat 3 (1951), H. 33, S. 333. Weiterhin stand an gleicher Stelle zu lesen, dass das Russian Research Center sich u. a. zur Aufgabe gemacht hatte, »soziologische, psychologische und politische Erkenntnisse über die Sowjetunion aus der Befragung der rund 500 ooo Flüchtlinge zu gewinnen, die sich außerhalb des sowjetischen Machtbereiches befinden«. Aus diesen und anderen Quellen speiste sich die »vorliegende Studie über Wlassow und seine Armee«, so die Redaktion.

130 Der veröffentlichte Aufsatz im Monat war ein Forschungsergebnis für ein Buch, das Fischer unter dem Titel Soviet Defection in World War II in den Vereinigten Staaten veröffentlichen wollte, so die redaktionelle Einleitung zu: George Fischer, Der Fall Wlassow, in: Der Monat 3 (1951), H. 33, S. 263. 
in diesem Kontext Aussagen sowie Deutungen über den Nationalsozialismus gemacht wurden), ${ }^{131}$

1. dass »Hitler einen ausgesprochenen >Vernichtungskrieg` gegen die Sowjetunion geführt hatte « ${ }^{132}$,

2. dass der »deutsche Blitzkrieg « die sowjetische Regierung »unvorbereitet« traf, ${ }^{133}$

3. dass hinsichtlich der »Ostpolitik des Dritten Reiches « sich die wesentlichste Tendenz dieser Politik

in dem Begriff des»Untermenschen«aus[drückt], eines Schlagwortes, das den Titel einer zu Beginn des deutsch-sowjetischen Krieges von den Dienststellen Himmlers herausgegebenen illustrierten Broschüre bildete. Quintessenz dieser Broschüre war die These, daß sich in der Bevölkerung Sowjetrußlands alles das verkörpere, was in der Menschheitsgeschichte mörderisch, barbarisch, räuberisch, »asiatisch« gewesen sei, wobei man immer wieder auf den Gegensatz zwischen dem lichten, von Ariern geführten Europa und dem von Untermenschen bevölkerten von Juden beherrschten Osten in Cestalt der Sowjetunion hinzuarbeiten versuchte, auf eine Haßbotschaft, die sich nicht nur gegen das Sowjetsystem, sondern gegen die Einwohner des Landes überhaupt richtete. ${ }^{134}$

4. dass diese »Himmler-Broschüre« nur eine gemeinverständliche Fassung dessen war, was den eigentlichen Kern der nationalsozialistischen Ostpolitik bildete, des Gedanken nämlich, dass die weiten und fruchtbaren Landstriche Rußlands angesichts der Unfähigkeit des minderwertigen Slawen, ein zivilisiertes Staatsgebilde hervorzubringen, den Interessen Deutschlands nutzbar gemacht werden müßten: sie sollten ein Neuland für die Kolonisierung durch Deutsche und andere Arier sein, die deutschen Kriegsanstrengungen durch die Lieferung von Rohstoffen und landwirtschaftlichen Erzeugnissen unterstützen und nach dem Siege Hitlers einen Absatzmarkt für die industriellen Erzeugnisse Europas bilden. ${ }^{135}$

5. dass der »Spiritus rector der >Untermenschenpolitik« Hitler selbst war. »Ihm zur Seite standen Reichsleiter Bormann und der Gauleiter von Ostpreußen Erich Koch, der bald zum Reichskommissar für die besetzte Ukraine ernannt werden sollte. «136

6. dass »eine zweite wesentliche Tendenz der deutschen Ostpolitik [...] auf dem von Alfred Rosenberg, dem späteren Reichsminister für die besetzten Ostgebiete, vertretenen Grundsatz >Teile und herrsche« fußte. Und mit Blick auf den Einfluss Rosenbergs hieß es weiter, dass dieser

131 Andrej A. Wlassow war sowjetischer Generalleutnant und »gefeierter sowjetischer Kriegsheld«, als er im Verlauf des deutschen Überfalls von der Wehrmacht gefangen genommen wurde und mit »deutscher Unterstützung die nach Hunderttausenden zählende >Russische Befreiungsarmee (ROA)< ins Leben rief.«(Redaktionelle Mitteilung, ebd.)

132 Ebd. (als Quelle diente: Der Untermensch, Berlin 1942).

133 Ebd., S. 265.

134 Ebd.

135 Ebd.

136 Ebd. 
im Laufe der Zeit immer mehr abzunehmen begann. Einmal deswegen, weil er infolge seiner verhältnismäßig weichen, fast femininen Art völlig außerstande war, sich gegen die Intrigen anderer Nazigrößen - vor allem Himmler und Coebbels durchzusetzen, ja nicht einmal gegen den ihm direkt unterstellten Reichskommissar für die besetzte Ukraine, Erich Koch aufkommen konnte. Zum anderen, weil Hitler im Gegensatz zu Rosenbergs Grundsatz des »Divide et impera « hartnäckig an der »Untermenschpolitik« festhielt, allen Bemühungen um eine Wiederbelebung unter den Russen - mochten sie noch so überzeugte Antistalinisten oder gar Kollaborateure sein - ablehnend gegenüberstand und letzten Endes nur das eine Ziel verfolgte, immer mehr Rohstoffe, Lebensmittel und Arbeitsplätze aus Rußland herauszupressen [...]. ${ }^{137}$

7. dass im Zusammenhang mit der NS-Führungsspitze beschlossenen Besatzungspolitik:

das verhältnismäßig zivilisierte Vorgehen der deutschen Fronttruppen« zu dem Zeitpunkt überschattet wurde, als die »Hitlersche Untermenschenpolitik sich, begünstigt durch den Druck der wirtschaftlichen Erfordernisse und der dem Nationalsozialismus innewohnenden Unmenschlichkeit, auf die ganze Kriegsmaschine auszuwirken begann. Deutsche Augenzeugenberichte haben kaum weniger als die alliierte Propaganda verbreitet, wie die Willkür der von der deutschen Regierung in den besetzten Gebieten ernannten Satrapen, die Massenmorde der SS-Einsatzkommandos - die vielleicht nur von den Grausamkeiten des sowjetischen NKWD übertroffen wurden - immer brutalere Formen annahmen. Nicht weniger schändlich war die Behandlung, insbesondere die Aushungerung von Millionen russischer Gefangener [...] und die immer rücksichtsloser werdende Zwangsverpflichtung oder Verschleppung russischer Arbeitskräfte [...]...138

8. Und schließlich, dass am 25. Oktober 1942 eine sogenannte Kritik an der Besatzungspolitik von Alfred Rosenberg, dem »Minister für die besetzten Ostgebiete", und seinem engsten Mitarbeiter Dr. Otto Bräutigam erfolgte, die folgendermaßen lautete:

1. Das Schicksal der sowjetischen Kriegsgefangenen ist im Cegenteil eine Tragödie von größtem Ausmaße. Von 3,6 Millionen Kriegsgefangenen sind heute nur noch einige Hunderttausend voll arbeitsfähig. Ein großer Teil von ihnen ist verhungert oder gestorben. Man kann ohne Übertreibung sagen, daß die Fehler in der Behandlung der Kriegsgefangenen in erheblichem Maße die Versteifung der Widerstandskraft der Roten Armee und damit den Tod von Tausenden deutscher Soldaten verursacht haben.

2. Die mir zugegangenen Berichte beweisen, daß die Methoden der Beschaffung von Arbeitskräften in diesen Cebieten als Gewaltmaßnahmen zur Massendeportation empfunden werden [...]. 
3. Im Osten wird von Deutschland ein dreifacher Krieg geführt: Ein Krieg zur Vernichtung des Bolschewismus, ein Krieg zur Zertrümmerung des Großrussischen Reiches und endlich ein Krieg zum Erwerb von Kolonialland zu Siedlungszwecken und zur wirtschaftlichen Ausbeutung.

Dieses dreifache Ziel des Ostfeldzuges hat den enormen Widerstand der Ostvölker hervorgerufen. Würde der Krieg nur mit dem Ziel der Zerstörung des Bolschewismus geführt, wäre er längst zu unseren Gunsten entschieden [.... ${ }^{139}$

Im Zusammenhang der Untersuchung über »Deutsche Meinungsverschiedenheiten über die Wlassow-Bewegung « - so die Überschrift eines Abschnittes im zweiten Teil seiner Veröffentlichung - kam Fischer auf Himmler zu sprechen und stellte unter anderem fest, dass dieser im Herbst 1943 »eine viel zitierte Ansprache vor der SS [hielt], in der er warnend sagte, die ehemaligen sowjetischen Soldaten sollten lieber einzeln als in geschlossenen Einheiten verwendet werden«. Zudem ging Fischer in diesem Kontext auf Himmlers "Memorandum vom 14. Oktober 1943« ein, in dem dieser ausführlich politisch-ideologisch gegen den »General Wlassow« Stellung bezog. Hierzu schrieb er unter anderem:

Rosenberg, der einen Teil der Kontrolle über die Ostpolitik zurückgewinnen wollte [...], stand der ganzen Wlassow-Bewegung von Anfang an sehr mißtrauisch gegenüber. Deshalb protegierte er nicht nur eine ganze Flut von extremistischen separatistischen »Nationalkomitees«, sondern auch die wlassowfeindlichen älteren Emigranten. Obwohl selbst sie zuweilen unter der »Untermensch «-Politik zu leiden hatten, wurden sie von Rosenberg in wachsendem Maße unterstützt und finanziert. Die extremen Elemente in der NSDAP hielten allerdings weiter an ihrer »Untermensch «-Politik fest, die eine so bequeme Rechtfertigung für die in Rußland begangenen Brutalitäten bot. Und da einer ihrer Vertreter, Bormann, von Himmler immer mehr ins Vertrauen gezogen wurde, übte sie auf die Aktionen des Führers einen beträchtlichen Einfluß aus. ${ }^{140}$

Für Fischer stand fest, dass Hitler bis Ende 1943 allen Plänen, die nicht seine »Untermensch «-Politik zur Voraussetzung hatte, eine klare Absage erteilte und er vielmehr darauf bestand, »Wlassows Funktion auf reine propagandistische Tätigkeit an der Front zu beschränken ${ }^{141}$. Daraus folgte für ihn auch, dass Wlassows »Befreiungsbewegung « politisch-militärisch nicht autonom agieren durfte, allerdings Sondereinheiten in der $»$ Waffen-SS $\ll^{142}$ stellte:

139 Ebd., S. $267 \mathrm{f}$.

140 Fischer, Der Fall Wlassow (Fortsetzung), S. 394.

141 Ebd., S. 395.

142 ZurWaffen-SS vgI. E[rnst]-U[Irich] Fromm, Prozeß gegen die Zeit. Ein Standgericht steht vor Gericht, in: Der Monat 10 (1958), H. 116, S. 69-78, der anlässlich des sogenannten Standgerichtsprozess Simon beim Schwurgericht beim Landgericht Nürnberg, der am 12. März 1957 mit der »Beweisaufnahme« begann, veröffentlicht wurde. Angeklagt waren der ehemalige SS-General Max Simon und fünf seiner früheren Untergebenen, die beschuldigt wurden, in den letzten Tagen des Zweiten Weltkrieges in Brettheim bei Rothenburg ob der Tauber einige Bewohner »wegen Wehrkraftzersetzung« zum Tode verurteilt und hingerichtet zu haben. 
Diese Einheiten wurden zur Partisanenbekämpfung und anderen Polizeiaufgaben in ganz Europa herangezogen. So waren die Kaminsky-Division und die Gil-Brigade zur Bekämpfung der Partisanen an der Ostfront eingesetzt, und die erstere beteiligte sich 1944 auch an der Niederschlagung des Warschauer Aufstandes. Im Jahre 1943 wurde in Ergänzung einer Galizischen (westukrainischen) SS-Division eine Ukrainische SS-Division aufgestellt, und ein Jahr später wurden verschiedene bjelorussische Einheiten in einer Bjelorussischen SS-Division zusammengefaßt. ${ }^{143}$

Nicht zuletzt durch die militärischen Niederlagen Deutschlands und durch die missglückte Verschwörung vom 20. Juli 1944 änderte sich, so Fischer, die »deutsche Ostpolitik«, die für ihn auch und vor allem zu einer zunehmenden Entfremdung zwischen Hitler und der Generalität führte sowie die »erstaunliche Zuhnahme der Macht Himmlers« zur Folge hatte. Denn: »Mehr denn je wurde die Wehrmacht bei wichtigen politischen Entscheidungen übergangen, Offiziere wurden durch zuverlässige Parteifunktionäre abgelöst. Das schlagendste Beispiel für diesen Prozeß war Himmler, der nach dem 20. Juli nicht nur Innenminister, sondern auch Befehlshaber des Ersatzheeres wurde und die vollständige Kontrolle der Wehrwirtschaft übernahm. «144

In den Augen von Fischer entschloss sich danach der »allmächtige Himmler«, seine bisherige »Untermensch«-Politik aufzugeben:

Dies wurde durch eine Denkschrift des leitenden Beamten für sowjetische Angelegenheiten im Propagandaministerium bestätigt, in der es heißt: »Das Verdienst, eine Pro-Wlassow-Politik durchgedrückt zu haben, gebührt Standartenführer Gunther d'Alquen, der sie dem Reichsführer SS mit der Überwachung der ganzen `Wlassow-Aktion betraut. Standartenführer d'Alquen, Chefredakteur des »Schwarzen Korps« und ehemalige Leiter des »Skorpions«, der SS-Propagandaabteilung für die Sowjetunion, übernahm jetzt auch die Ostpropagandaabteilung der Wehrmacht, die bis dahin alle Unternehmen Wlassows mit aus der Tiefe gehoben und protegiert hatte. Ein anderer SS-Standartenführer, Kröger, löste Hauptmann Strikfeldt als Verbindungsoffizier bei Wlassow ab. ${ }^{145}$

Fischer zufolge entsprach es indessen dem totalitären NS-System, auch in der Schlussphase keine fundamentale Änderung seiner »Ostpolitik« vorgenommen zu haben, sodass noch in der »schwersten Krise« das Misstrauen gegenüber Wlassow dominierte und ihm keine "volle Selbstständigkeit« gewährt wurde. Denn hinsichtlich der Frage, »wie lange eine groß aufgezogene Wlassow-Bewegung den Zusammenbruch des Dritten Reiches aufhalten konnte«, ermangelte es, so der Autor, dem nationalsozialistischen Deutschland an einer flexiblen Haltung und zeigte sich die »dogmatische Enge seines Systems«. Denn: »Viel wichtiger waren die Rassenlehre, der Expansionsdrang und die Kolonisationsbestrebungen des Hitlerismus. $\aleph^{146}$

143 Fischer, Der Fall Wlassow (Fortsetzung), S. 396.

144 Ebd., S. 399.

145 Ebd., S. 400.

146 Ebd., S. 403. Zur nationalsozialistischen Besatzungspolitik in der Sowjetunion vgl. auch die eher allgemein gehaltenen Ausführungen im Rahmen des Beitrages: F[ritz] R[ené] Allemann, Die Rußlandpolitik des Dritten Reiches, in: Der Monat 3 (1951), H. 32, S. 199-202 (Rezension). 
Abgesehen von den genannten Beiträgen zur nationalsozialistischen Diplomatie und Außenpolitik seit dem »Anschluss« Österreichs im Jahre 1938 sowie zum Zweiten Weltkrieg ${ }^{147}$ untersuchte bzw. thematisierte der Monat den Verlauf sowie die Ereignisse des Krieges vor allem im Kontext der nach dem Zusammenbruch des >Dritten Reiches im Mai 1945 erschienenen »Memoirenliteratur«. Anders gesagt: Insbesondere in der kritischen Auseinandersetzung mit den Buchveröffentlichungen von ehemaligen Wehrmachtsoffizieren und -generälen, Soldaten der Wehrmacht sowie führenden Funktionären des NS-Systems gewann man als Leser des Monat auch nähere Einzelheiten über den »Führerstaat«, über die außenpolitischen Ziele und Motive sowie über einzelne Aspekte des Weltanschauungskrieges gegen die Sowjetunion. Hierbei nutzten gewissermaßen die Autoren des Monat die kritische Auseinandersetzung mit der »Memoirenliteratur«, die in vielen Fällen ausschließlich »Rechtfertigungsschrift[en] « (de Mendelssohn) darstellten, um einerseits jedweden Versuch die nationalsozialistischen Verbrechen infrage zu stellen oder zu relativieren, eindeutig zu widersprechen sowie andererseits, um auch auf den deutschen Widerstand gegen das »Hitler-Regime« einzugehen. In diesem Zusammenhang werden im Folgenden die zentralen Kernaussagen und -interpretationen in Bezug auf den »Führerstaat « genutzt, um anhand einzelner, repräsentativer Veröffentlichungen der Autoren auch die »Analyse des Nationalsozialismus« weiterzuführen. Da es aus Raumgründen unmöglich ist, auf jeden einzelnen Beitrag einzugehen, können nur einzelne Veröffentlichungen, die einen repräsentativen Charakter besitzen, berücksichtigt werden.

Mit der Rezension des Buches Stalingrad von Theodor Plivier begann die Thematisierung der »Memoirenliteratur« im Monat. Der Autor, Robert Gorham Davis, stellte zu Anfang fest, dass der Roman von Plivier »der eindrucksvollste Roman des Zweiten Weltkrieges« sei, »wuchtig, glänzend in der Darstellung und furchtbar in seiner erbarmungslos bis in die Einzelheiten gehende Beschreibung der Vernichtung«. Davis sah in der Beschreibung des "schrecklichen, menschenunwürdigen Massenkampfes und der Abstumpfung des Frontkämpfers gegen Grausamkeit und Schmerz « auch und vor allem (literarische) Parallelen zu dem Roman über den Ersten Weltkrieg Im Westen nichts Neues von Erich Maria Remarque (1929). Indessen handelte Pliviers Buch, so der Rezensent,

um die sechste deutsche Armee unter Ceneral von Paulus, die verzweifelt gegen die Entschlossenheit der ankämpft, die Industriestadt Stalingrad zum Verdun des Zweiten Weltkrieges zu machen. Als die sechste Armee mit ihren mehreren hunderttausend Mann abgeschnitten wird, gibt Hitler den Befehl, sich einzuigeln und bis zum letzten Mann Widerstand zu leisten. Die von Cöring zugesicherte Versorgung durch die Luft erweist sich als unzureichend, und innerhalb von sechs Wochen ist die Armee auf die Hälfte zusammengeschmolzen. Die Soldaten sind an den Tod gewöhnt, selbst an den Massentod, doch in ihrer gemeinsamen Abgeschnittenheit inmitten der Katastrophe

147 Vgl. auch allerdings mit dem Schwerpunkt auf die Außen- und Kriegspolitik der Vereinigten Staaten in Westeuropa: Hanson W. Baldwin, Der Kampf um Europa, in: Der Monat 4 (1952), H. 46, S. 417-422 (Rezension). 
fühlen sie ein neues Zusammengehörigkeitsgefühl, und es wird ihnen klar, daß ein Mann allein eine ganze Armee zu einem im Crunde sinnlosen Tod verurteilt. ${ }^{148}$

In verschiedenen Beiträgen setzte sich auch Trevor-Roper ${ }^{149}$ mit der »Memoirenliteratur « und auf dieser Grundlage mit dem nationalsozialistischen Herrschaftsregime auseinander. Nämlich insofern, als er durch die Rezension von Buchpublikationen ehemaliger Wehrmachtsgeneräle substanzielle Reflexionen und Deutungen zum Nationalsozialismus vornahm und zudem die Rolle ebendieser Funktionsträger im Herrschaftsgefüge des »Führerstaates« (sowie im Zweiten Weltkrieg) beleuchtete. Unter der Überschrift »Die Generäle verteidigen sich« besprach Trevor-Roper bereits im Jahre 1949 in Heft 14 die Veröffentlichungen Hitler als Feldherr von Franz Halder sowie Von der militärischen Verantwortlichkeit in der Zeit vor dem Zweiten Weltkrieg von Friedrich Hoßbach. ${ }^{150}$

Trevor-Roper berichtete über General Friedrich Hoßbach, dass dieser vorübergehend »Hitlers Adjutant war und auch das Protokoll der berühmten Konferenz vom 5. November 1937 geführt hatte, in dem Hitler den Chefs der drei Waffengattungen sein >politisches Testament bekanntgab«. Und weiter: »Auf die Jahre vor dem Krieg zurückblickend, erkennt Hoßbach, wie wir alle es heute tun können, daß dieser Konferenz grundsätzliche Bedeutung zukam.«Über Hitler hieß es in diesem Zusammenhang, dass dieser mit der

Beseitigung von Fritsch und Beck und durch die Bildung des Oberkommandos der Wehrmacht unter seinem Gefolgsmann Keitel die Armee den Händen der Ceneräle entrissen (hatte): [...] Schließlich hatte er in der berühmten Konferenz eine undurchführbare Politik der unbegrenzten Aggression angekündigt, welche die Armeeführer nicht vorausgesehen hatten und für die sie heute die Verantwortung ablehnen. Die Ereignisse, die zu der Niederlage Deutschlands führten, waren also nicht auf die Generäle, sondern auf Hitler zurückzuführen. Das ist der Kern von Hoßbachs kleiner Schrift. ${ }^{151}$

Die Ausführungen von Hoßbach reichten laut Trever-Roper bis August $1939^{152}$ und bezogen sich zeitlich somit nur bis zum offiziellen Rücktritt von Ludwig Beck ${ }^{153}$ von seinem Posten als »Chef des Generalstabes«, der »den Bruch zwischen Heer und Partei«

148 Robert Gorham Davis, Pliviers »Stalingrad«in Amerika, in: Der Monat 1 (1948), H. 3, S. 102 f., hier S. 102 (Rezension). Vgl. auch H. K., Das Grab der goldenen Türme, in: Der Monat 5 (1954), H. 54, S. 664-666. Dort schrieb der am Krieg gegen die Sowjetunion an der »Front« teilnehmende Rezensent auf Seite 665, dass auch der Buchautor, d. h. Plivier, hinsichtlich des »berüchtigten $* K o m m i s s a r e r l a ß «$ «usste, dass »politische Kommissare als Nichtkombattanten zu betrachten und an Ort und Stelle ihrer Cefangennahme vorwärts der Regimentsgefechtsstände zu erschießen seien«.

149 Siehe zu Trevor-Roper speziell das nachfolgende Kap. IV.1.9.

150 Hugh R. Trevor-Roper, Die Generäle verteidigen sich, in: Der Monat 2 (1949), H. 14, S. $210-213$ (Sammelrezension).

151 Ebd., S. 210.

152 Hier muss es sich um ein Versehen oder um einen Druckfehler im Beitrag von Trever-Roper gehandelt haben, denn gemeint sein konnte nur der August 1938. Das Rücktrittsgesuch des Ceneralstabschefs des Heeres, Ludwig Beck, erfolgte am 18. August 1938.

153 Vgl. hierzu auch bes. Butler, Der Fall Fritsch. 
kennzeichnete. ${ }^{154}$ An diesem Punkt, so Trevor-Roper, setzte die historische Darstellung Hitler als Feldherr von Halder ein, der nämlich Nachfolger von Beck als Chef des Generalstabes wurde und dessen Buch nur den Kontext bis Ende des Jahres 1942 abdecken konnte. ${ }^{155}$ Trevor-Roper bemerkte unter anderem, dass an dem Band insofern Zweifel an der Richtigkeit der Darstellung anzubringen waren, als nämlich Halder »noch immer« behauptete:

Hitler sei persönlich für die taktischen Befehle verantwortlich gewesen, die zum Verhalten der deutschen Panzerspitzen führten und so der englischen Armee die Möglichkeit gaben, aus der Umkreisung von Dünkirchen zu entkommen. Er übersieht dabei völlig die Aussage Churchills, wonach die Initiative zu diesem Schritt nicht von Hitler, sondern von Rundstedt ausging. Innerhalb dieser Einschränkung kann jedoch gesagt werden, daß Halders Werk klar und fachmännisch geschrieben ist. Er beweist, daß Hitler tatsächlich selbst den Krieg geführt habe, insofern es ihm gelungen war, der ganzen Kriegsmaschine seinen Geist einzuhauchen und sie anzutreiben; es fehlten ihm jedoch die Merkmale eines großen Feldherren, und seine strategischen Prinzipien waren ausgesprochen verhängnisvoll.

Nachdem Halder in seiner Untersuchung Hitler als Feldherrn in drei »wichtigen Punkten« verurteilte, gelangte Trevor-Roper mit Blick auf Halder (sowie Hoßbach) zu folgendem historischem Urteil:

Das von Halder vorgelegte Material, [...], ist so überwältigend, daß der Leser sich wundern muß, wie Halder seinem obersten Kriegsherrn so lange dienen konnte. Man muß also mit Hoßbach übereinstimmen, der ganz klar feststellt, daß Halder, nachdem er die Stellung Becks zu Hitlers Bedingungen angenommen hatte, die wirklichen Prinzipien verraten hatte, durch die sich die Wehrmacht von der Partei unterschied - die Prinzipien, auf die sich heute die Sache der deutschen Generäle stützt, die aber nur Beck wirklich von seinem Rücktritt im Jahre 1939 bis zu seinem Selbstmord nach dem Mißlingen des Anschlags vom 20. Juli 1944 aufrechtgehalten hatte. ${ }^{156}$

Neben weiteren Beiträgen zum Themenkomplex Zweiter Weltkrieg ${ }^{157}$ kam der Monat auf das »Unternehmen Barbarossa« im Zusammenhang der Thematisierung des Inter-

154 Trevor-Roper, Die Generäle verteidigen sich, S. 210.

155 Nach Angabe von Trevor-Roper (ebd., S. 211) wurde Halder 1942 von seinem Posten enthoben, weil Hitler selbst seine Funktion des »Feldherrn « übernahm, und im Juli 1944 aufgrund des Verdachts, an der »Ceneralsverschwörung beteiligt gewesen zu sein, in ein Konzentrationslager geschickt«.

156 Ebd., S. 211.

157 Siehe zur »Kollaboration« Pierre Lavals mit »Hitlerdeutschland«: Theodor Draper, Realist oder Opportunist?, in: Der Monat 1 (1949), H. 10, S. 98 f. (Rezension); zum Überfall Frankreichs durch die Wehrmacht und zur darauffolgenden deutschen Besatzungspolitik unter Otto Abetz im besetzten Paris: Stefan T. Possany, Otto Abetz als Friedensapostel, in: Der Monat 5 (1952), H. 49, S. 94-97 (Rezension); siehe auch die kontroverse Diskussion über methodische Aspekte anlässlich des Buches Geschichte des zweiten Weltkrieges in Dokumenten von Michael Freund zwischen Freund und Hofer, die durch eine im Monat (unter dem Titel Zeitgeschichte-so oder so?) in deutscher Übersetzung veröffentlichte Rezension aus der Londoner Zeitschrift Economist ausgelöst wurde: Der Monat 6 (1954), H. 70, S. 407 ff., sowie hierzu den kritischen Kommentar von Hofer in: Der Monat 6 (1954), H. 72, S. 604 ff. 
nationalen Nürnberger Militärtribunals ${ }^{158}$ sowie nachfolgenden amerikanischen und britischen Militärverfahren zu sprechen und ging hierbei speziell auf die Rolle der Wehrmacht, genauer, des »Generalstabes und des OKW« (Oberkommando der Wehrmacht) ein: Nämlich in der Besprechung des Buches Verteidigung deutscher Soldaten. Plädoyers vor alliierten Gerichten von Hans Laternser, dem prominenten Verteidiger im Nürnberger Hauptverfahren und in den Prozessen gegen das OKW und die Südostgeneräle sowie in einem britischen Gerichtsverfahren gegen hohe deutsche Militärs in Venedig, durch den deutschen Historiker Walter Görlitz. ${ }^{159}$

Abgesehen von der Tatsache, dass im Nürnberger Hauptkriegsverbrecherprozess, so Görlitz vor dem Hintergrund der »Leugnung aller Menschenrechte durch Hitler « im Zweiten Weltkrieg, naheliegenderweise die Verstöße gegen das damals geltende Kriegs- und Völkerrecht beleuchtet wurden, thematisierte er auch das Verhältnis des Generalstabes und des OKW zu Hitler. In diesem Kontext konstatierte er, dass es sich in Nürnberg nicht beweisen ließ, dass der »Generalstab und OKW « als eine homogene Gruppe anzusehen sei. Folglich erwies sich der Versuch der Anklage, »unter der Sammelbezeichnung `Generalstab das Korps der hohen militärischen Führer zu erfassen«, als nicht richtig heraus. Denn, so das Urteil von Görlitz:

Er zeigte deutlich, wie schwer es für die Anklagevertretung war, den höchst komplizierten, vielfältig verschachtelten Bereich der deutschen Kriegsspitzengliederung zu entwirren. Das Bild des Hitlerschen >Führerstaates` verleitete zu der Vorstellung von einer straffen Gliederung. Allmählich mußte man jedoch erkennen, daß man auf diesem Weg nicht weiter kam, daß auch der Begriff der `Verschwörung`zwischen NSDAP, Generalstab und Schwerindustrie viel zu schablonenhaft war. Der `Führerstaat $<$ mit seinem Cewirr von Stäben, sich überschneidenden Führungsbereichen und einander auf das heftigste befehdenden Machthabern glich im Grunde einer verhüllten diktatorischen Anarchie. ${ }^{160}$

158 Vgl. Walter Hasenclever, Klar zum Tauchen. Die lückenhaften Erinnerungen eines Großadmirals, in: Der Monat 11 (1959), H. 125, S. 78-81 (Rezension). Beispielsweise stellte Hasenclever auf S. 78 fest, dass der Erinnerungsband Dönitz' »keine einzige handgreifliche Lüge« enthält, gleichwohl hatte das Buch »mit Wahrheit, mit geschichtlicher Wahrheit« wenig zu tun. Darüber hinaus konstatierte er, dass Dönitz »nichts mit Partisanen und Geiselerschießungen, mit SS-Verbänden, Judenausrottungen und dem Haß besetzter Völkerschaften zu tun« hatte. Und weiter hieß es hinsichtlich der Erklärung vom »Herrn Großadmiral« bei dessen Ansprache zum »Heldengedenktag« am 12. März 1944: " Was wäre aus unserer Heimat heute, wenn der Führer uns nicht im Nationalsozialismus geeint hätte? Zerrissen in Parteien, durchgesetzt von dem auflösenden Cift des Judentums und diesem zugänglich, wären wir längst der Belastung dieses Krieges erlegen und der erbarmungslosen Vernichtung unserer Gegner ausgeliefert worden.< Man macht sich also die kompromißlose Weltanschauung gegen das Judentum zu eigen, rümpft aber ablehnend die Nase, wenn dabei die Schaufenster der jüdischen Geschäfte in Trümmern gehen.«(Ebd., S. 80)

159 Walter Görlitz, Schuld oder Schicksal?, in: Der Monat 3 (1951), H. 28, S. 429-432 (Rezension). Laternser verteidigte im Nürnberger Hauptverfahren den Ceneralstab und das OKW als Cruppe sowie die Ceneralfeldmarschälle Wilhelm List im Nürnberger Prozess gegen die »Südost-Generale« (Fall 12), Wilhelm Ritter von Leeb im Nürnberger OKW-Prozess (Fall 12) und Albert Kesselring im Verfahren vor einem britischen Militärgericht 1947 in Venedig. 
Seiner Ansicht nach bildeten in dieser »diktatorischen Anarchie« Teile des Offizierskorps »Zentren der Opposition«. Falsch war für Görlitz die Vorstellung, dass der Generalstab am Ausbruch bzw. an der »Entfesselung des zweiten Weltkrieges beteiligt war«. Zweifelsohne gab es im Generalstab Befürworter eines Krieges um »jeden Preis« - wie zum Beispiel Waldersee oder Ludendorff; und insbesondere Letzterer war der Ideengeber des »totalen Krieges«. Gleichwohl existierten für den Rezensenten auch »Gegenkräfte«, wie beispielsweise die Wehrmachtsgeneräle Kesselring, List und Leeb, die als Exponenten der traditionsbewussten alten Offiziersgeneration und Theoretiker die Aufgabe des Generalstabs darin sahen, »die Vorbereitung der Verteidigung des Reichsgebietes« zu garantieren. Folglich waren sie »scharfe Gegner« von Ludendorff und sahen sich in den Augen von Görlitz »als führende Soldaten hineingestellt in den Zusammenstoß dieser Defensivtheorie mit den Aggressionsplänen Hitlers. Dies wurde ihnen zum Verhängnis« ${ }^{161}$

Vor dem Hintergrund des neuartigen Phänomens des Partisanenkriegs, mit dem die deutsche Seite nach dem Überfall auf die Sowjetunion konfrontiert war, ${ }^{162}$ war Görlitz der Meinung, dass zwei Befehle Hitlers, die für ihn zweifelsohne gegen alle »herkömmlichen Regeln« des bis dahin geltenden Kriegsvölkerrechtes verstießen, in dem angesprochenen Kontext besonders bemerkenswert waren: einerseits der >Kommissar-Befehk, der »die Ausrottung der Träger der ketzerischen Weltanschauung bei der feindlichen Armee verlangte«, und andererseits der >Barbarossa-Befehk über die Militärgerichtsbarkeit, »der die Aufhebung des Verfolgungszwanges bei Straftaten von Soldaten gegen Zivilpersonen in den Ostgebieten vorsah«. Indes: Nach Meinung von Görlitz hatten die meisten Heeresgruppen- und Armeekommandeure diese »Befehle abgelehnt«, namentlich der Oberbefehlshaber des Heeres, Feldmarschall von Brauchitsch - der, wie es bei Görlitz hieß, versuchte, den >Manneszucht-Befehk zu durchkreuzen - sowie Generaloberst Zeitzler, der als Generalstabschef des Heeres schließlich die »Aufhebung des Kommissar-Befehls« durchsetzte.

Im Zusammenhang mit der Thematisierung des Partisanenkrieges kam Görlitz auch und vor allem auf die sogenannten Einsatzgruppen zu sprechen (die nach dem Überfall der Wehrmacht auf Polen gebildet wurden). Hierzu schrieb er:

Der Partisanenkrieg mit der Kette der zwangsläufig ausgelösten Repressalien, der Ceiselfestnahmen und Massenhinrichtungen, dem Niederbrennen von Ortschaften, den Deportationen, der Internierung gewisser Bevölkerungstruppen in Sammellagern, mit den umstrittenen Fragenkomplexen des Status illegaler Kombattanten-Gruppen und -Armeen und der Legalität oder Illegalität innerpolitischer Widerstandsbewegungen

161 Alle Zitate ebd., S. 430. Und weiter schrieb Cörlitz an dieser Stelle zu Adolf Hitler: »Hitler, der dämonische, besessene Demagoge, war als Führer einer autoritären Massenpartei eine völlig neue Erscheinung in der deutschen Geschichte. Für ihn wurde der Krieg schließlich zum Weltanschauungskampf zwischen den sSozialregionen`, die bei den entgötterten Massen an die Stelle der alten echten Kirchen getreten waren. Im Kampf gegen den Bolschewismus erblickte er im Grunde die Ausrottung einer ketzerischen Claubenslehre. Infolgedessen zeitigte dieser Krieg völlig neue Formen, beziehungsweise die Wiederkehr sehr altertümlicher Vorstellungsbereiche.« (Ebd., S. 430 f.)

162 Görlitz wies darauf hin, dass der Partisanenkrieg im Zweiten Weltkrieg zu »den neuen Formen« gehörte, wie »er Kesselring in Italien, List auf dem Balkan, Leeb in Rußland entgegentrat« (ebd., S. 431). Vgl. auch zum »Partisanenkampf « in Jugoslawien die Ausführungen von Hans Schwab-Felisch, »Die letzte Brücke«. Die Entstehungsgeschichte eines Films, in: Der Monat 6 (1954), H. 71, S. 475-684. 
zieht sich wie ein roter Faden durch das Buch Laternsers. Der Anwalt bemüht sich, Anklagepunkte zu entkräften, Kompetenzen zu ordnen und zu begrenzen, so schauerlichen Erscheinungen wie den >Einsatzgruppen des SD ihren richtigen Platz innerhalb des Cefüges der verschiedenen Befehlsbereiche zuzuweisen. Er überzeugt oft, jedoch nicht immer. Die ärgste Schwierigkeit bei der Erörterung all dieser Dinge liegt im Bereich des Rechts selbst, liegt in dem, was englische Völkerrechtler, welche Laternser freigebig zitiert, als die $>$ Unbestimmtheit des Kriegsrechtes $<$ bezeichnet haben. ${ }^{163}$

Darüber hinaus ging Görlitz neben den angedeuteten Aspekten des internationalen Kriegs- und Völkerrechtes ${ }^{164}$ sowie der (individuellen) »Schuldfrage « zweimal auf die Einsatzgruppen ein. Zum einen beim »Fall Kesselring«. Hier schrieb Görlitz:

Kesselring etwa hatte, im Gegensatz zu den Heeresgruppenbefehlshabern in Rußland, in Italien auch die Befugnis eines Territorialbefehlshabers. Mußte er sich in schwierigster militärischer Lage auflehnen, als die Liquidierung von Hunderten von Ceiseln dem ihm nicht unterstehenden SD überantwortet wurde? Die Antwort kann kein irdisches Cericht entscheiden, sie steht dem Menschen $\mathrm{zu}^{165}$

Zum anderen ging er im Zusammenhang mit der »deutschen militärischen Résistance« auf die Einsatzgruppen ein. Hier hieß es bei Görlitz: »Es sollte nachdenklich stimmen, wenn ausgerechnet Führer von SD-Einsatzgruppen, Massenmörder vom Schlage eines Ohlendorf, die alte Offiziersgeneration anklagen, in der sie ihre alten Gegner erblicken. «"166

\subsection{Die Memoirenliteratur und der deutsche Widerstand gegen den Nationalsozialismus oder: das "Erinnerungsbuch " Ernst von Weizsäckers}

Im Zusammenhang mit der Auseinandersetzung der Memoirenliteratur soll im Folgenden ausschließlich auf den Beitrag Die verhinderten Hochverräter. Wege und Irrwege neuerer deutscher Memoirenliteratur von de Mendelssohn ${ }^{167}$ eingegangen werden. Dies erfolgt aus mehreren Gründen. Die Darstellung verkörperte - im Vergleich zu den bereits genannten Artikeln sowie weiteren Beiträgen zur Memoirenliteratur im Mo-

163 Ebd., S. 431.

164 Ich komme auf diesen Punkt im Schlussteil eingehend zu sprechen.

165 Ebd., S. 431.

166 Ebd., S. 432. Vgl. auch die Ausführungen über Otto Ohlendorf und über seine Rolle in der SS und im RSHA, die sich nach Gerhard Ritter »zu einer Art von Zentralbehörde des `Himmler-Staates« entwickelte - ohne indes auf die spezielle Bedeutung und Aufgaben der Einsatzgruppen im Kontext des Zweiten Weltkrieges einzugehen und ohne die Rolle Ohlendorfs als Leiter der »Einsatzgruppe D«zu beleuchten: Gerhard Ritter, Carl Coerdeler und das Ende des deutschen Widerstandes, in: Der Monat 7 (1955), H. 77, S. 387-401, hier S. 392 f.

167 Peter de Mendelssohn, Die verhinderten Hochverräter. Wege und Irrwege neuerer deutscher Memoirenliteratur, in: Der Monat 3 (1951), H. 29, S. 495-509 ([Sammel-]Rezension). Vgl. auch ders., Kritiker auf schlechtem Sitzplatz, in: Der Monat 4 (1952), H. 41, S. 544-546 (hierbei handelte es sich um die Besprechung des Buches: Dr. Paul Schmidt, Der Statist auf der Galerie 1945 bis 1950/Erlebnisse, Kommentare, Vergleiche, Bonn o. J). 